\title{
Esterco bovino líquido em luvissolo sódico: II. Emergência e análise de crescimento do maracujazeiro amarelo ${ }^{1}$
}

\author{
Liquid bovine manure in luvissol sodic: II. Emergence and growth analysis \\ of the yellow passion plants
Vinícius Batista Campos ${ }^{2}$, Lourival Ferreira Cavalcante ${ }^{3,7}$, Stella da Silva Prazeres-Campos ${ }^{4}$, Hans Raj Gheyi ${ }^{5,7}$, Lúcia Helena Garófalo Chaves ${ }^{6,7}$, Lécio Resende Pereira Júnior ${ }^{3}$

\begin{abstract}
RESUMO
Um experimento foi desenvolvido em casa de vegetação em blocos em parcelas subdivididas com objetivo de avaliar a emergência e análise de crescimento do maracujazeiro amarelo num solo sódico submetido à aplicação de biofertilizante bovino líquido aplicado ao solo aos níveis percentuais de $0,25,50,75$ e $100 \%$ em volume correspondente a $10 \%$ (250 mL) do volume do substrato para avaliação das plantas aos 45, 60, 75, 90 e 105 dias após a semeadura. O fornecimento do biofertilizante foi realizado em duas etapas: a primeira aos 30 dias antes da semeadura mais lavagem dois dias após a aplicação e a segunda 48 horas antes da semeadura procedendo a lavagem semelhante a primeira aplicação. As plantas foram irrigadas com água não salina $(\mathrm{CE}=0,21 \mathrm{dS}$ $\mathrm{m}^{-1}$ ) fornecendo o volume de água evapotranspirado de cada 24 horas com base no processo de pesagem. O desbaste das plântulas foi realizado aos 28 dias após a semeadura deixando-se apenas uma planta por unidade experimental. O percentual de emergência do maracujazeiro amarelo foi superior nos tratamentos com maior percentagem de biofertilizante adicionado, além do insumo proporcionar maior taxa de crescimento absoluto das plantas.
\end{abstract}

Palavras-chave: Passiflora edulis Sims Deg, biofertilizante bovino, taxa de crescimento absoluto.

\section{SUMMARY}

An experiment was carried out in green house in order to evaluate at initial growth of yellow passion plants submitted to application of liquid bovine biofertilizer applied to soil in liquid form to levels equivalent to $0,25,50,75$ and $100 \%$ in volume corresponding to $10 \%(250 \mathrm{~mL})$ of volume of the substrate and plant evaluation at five ages 45, 60, 75, 90 and 105 days after sowing. The supply of biofertilizer was applied in two epochs. The first 30 days the before the sowing followed by soil washing two days after application of biofertilizer and the second 48 hours before sowing and soil washing. The plants were irrigated with non saline water $\left(\mathrm{EC}=0.21 \mathrm{dS} \mathrm{m}^{-1}\right)$ adding water volume equivalent to evapotranspirat during 24 hours. The emergence of yellow passion fruit plants was superior in treatments with higher levels of biofertilizer applied to soil, over there of organic product provide more absolute growth rate of plants.

Key words: Passiflora edulis Sims Deg, bovine biofertilizer, absolute growth rate.

\section{Introdução}

Dentre os estresses que interferem negativamente os vegetais, Marscnher (1995), citam os estresses de temperatura, hídrico e os minerais. Este último se refere às condições de nutrição vegetal inorgânica, isto é, a fatores edáficos, relacionados ao solo. Para
Zhu (2001), os sais do solo são o principal estresse abiótico das plantas cultiváveis do mundo.

O processo de salinização dos solos ocorre por diversos fatores. O mais frequente é o de origem litólica. A geomorfologia também exerce seu papel, uma vez que a existência de depressões ou a baixa declividade pode promover a acumulação dos sais

1 Parte da dissertação apresentada ao Programa de Pós-Graduação em Manejo de Solo e Água do CCA/UFPB.

2 Instituto Federal de Educação, Ciência e Tecnologia do Amapá, Campus Laranjal do Jari, AP. CEP: 68920-000, doutorando em Engenharia Agrícola, CTRN, UFCG. Bolsista CNPq. E-mail: vinicius.campos@ifap.edu.br

3 Universidade Federal da Paraíba, Departamento de Solos e Engenharia Rural, Areia, PB.

4 Universidade Federal do Ceará, Programa de Pós-Graduação em Solos e Nutrição de Plantas, Fortaleza, CE.

5 Universidade Federal do Recôncavo da Bahia, Núcleo de Engenharia de Água e Solo, Cruz das Almas, BA.

6 Universidade Federal de Campina Grande, Unidade Acadêmica de Engenharia Agrícola, Campina Grande, PB.

7 Pesquisador INCTSal.

Fecha de Recepción: 16 Agosto, 2010.

Fecha de Aceptación: 06 Enero, 2011. 
(Bissani et al., 2006). A expansão das áreas afetadas por sais vêm se crescendo anualmente. Em nível mundial, $25 \%$ de toda área submetida à irrigação encontram-se comprometidas por sais. No Brasil são aproximadamente nove milhões de hectares em sete Estados do Nordeste. Na Bahia se localiza a maior área de solos degradados por sais, com cerca de $44 \%$ dos solos sendo afetados por sais, seguido do Ceará, com 25,5\% (Carneiro et al., 2002).

A fisiologia da resistência das plantas à salinidade tem sido estudada em muitos trabalhos, onde se procura verificar os mecanismos de adaptação a essas condições. A porcentagem de germinação das sementes em substrato salino tem sido um dos métodos mais difundidos para determinação dessa tolerância. A redução desta variável quando comparada ao controle, serve como indicador da tolerância da espécie à salinidade. A inibição do crescimento ocasionada pela salinidade se deve tanto ao efeito osmótico, ou seja, à seca fisiológica produzida, como ao efeito tóxico, resultante da concentração de íons no protoplasma (Garcia et al., 2007). As sementes são sensíveis aos efeitos da salinidade e, quando semeadas em soluções salinas, observa-se inicialmente uma diminuição na absorção de água (Munns et al., 2002; Silva et al., 2008). No caso das sementes, o efeito dos sais reduz a velocidade de embebição, diminuindo a velocidade de germinação. Os processos de divisão e expansão celular também podem apresentar alterações, assim como a mobilização das reservas indispensáveis para que ocorra o processo germinativo (Cavalcante et al., 2007). Segundo Meza et al. (2007), ao avaliarem o efeito da salinidade sobre a germinação e emergência de sementes de maracujá na Venezuela, constataram que o processo germinativo e a percentagem de emergência foram afetados significativamente pela salinidade da água de irrigação.

O uso de produtos como gesso agrícola, cloreto de cálcio, ácido sulfúrico e formadores de ácidos, minimizam os efeitos adversos dos sais às sementes e plantas. Entretanto, em tempos de aquecimento global, novas tecnologias vêm sendo pesquisadas para mitigar a influência negativa da salinidade às culturas e, dentre elas, o biofertilizante, apresenta respostas positivas sob irrigação com água salina na germinação de sementes de maracujazeiro amarelo (Sousa, 2006) e crescimento inicial da mamoneira (Campos et al., 2009) e goiabeira (Cavalcante et al., 2010), porém os estudos com os efeitos adversos do sais presentes no solo são escassos na literatura.
Nesse sentido, objetivou-se avaliar a emergência de plântulas e análise de crescimento do maracujá amarelo submetido à aplicação de biofertilizante bovino líquido em Luvissolo sódico.

\section{Material e Métodos}

\section{Área de estudo}

A pesquisa foi conduzida, no período de agosto a dezembro de 2008, em casa de vegetação do Departamento de Solos e Engenharia Rural (DSER), do Centro de Ciências Agrárias (CCA) - Campus II, Universidade Federal da Paraíba (UFPB), no município de Areia-PB, localizada na microrregião do Brejo paraibano e pelos pontos das coordenadas geográficas: 6 $6^{\circ} 58^{\prime} 12^{\prime \prime}$ de latitude Sul, $35^{\circ} 42^{\prime} 15^{\prime}$ " de longitude a Oeste de Greenwich com $619 \mathrm{~m}$ de altitude.

Segundo a classificação de Köppen, o clima da região pertence ao subtipo climático que corresponde ao clima tropical sub-úmido (quente úmido, com chuvas de março a agosto), temperatura média anual oscilando entre 22 e $26^{\circ} \mathrm{C}$ e umidade relativa do ar entre 75 e $87 \%$. Os dados referentes à temperatura média e umidade relativa do ar da área experimental no período de condução da pesquisa encontram-se na Figura 1.

Como substrato, foi utilizado material de um LUVISSOLO CRÔMICO caráter sódico proveniente da Escola Agrotécnica de Sousa - PB, coletados na profundidade $0-20 \mathrm{~cm}$ do perfil. Após a coleta, o material de solo foi destorroado e posto para secar ao ar na sombra; em seguida foi passado em peneira de malha de seis $\mathrm{mm}$. Desse material foram retiradas amostras passadas na peneira de $2 \mathrm{~mm}$ de malha, obtendo-se a terra fina seca ao ar (TFSA), para a caracterização física e química, nos Laboratórios de Física, Química e fertilidade do solo do DSER/ CCA/UFPB. Fisicamente o solo apresentava 652, 306,42 e $25 \mathrm{~g} \mathrm{~kg}^{-1}$ de areia, silte, argila e argila dispersa em água, respectivamente; densidade do solo e de partículas de 1,71 e $2,66 \mathrm{~kg} \mathrm{dm}^{-3}$, resultando numa porosidade total de $0,35 \mathrm{~m}^{3} \mathrm{~m}^{-3}$ e valor de água disponível de $17,8 \mathrm{~g} \mathrm{~kg}^{-1}$. Quanto aos atributos de fertilidade, foi caracterizado como alcalino ( $\mathrm{pH}=9,46)$, com os seguintes teores: $\mathrm{P}(\mathrm{mg}$ $\left.\mathrm{dm}^{-3}\right)=71,06 ; \mathrm{K}^{+}\left(\mathrm{cmol}_{\mathrm{c}} \mathrm{dm}^{-3}\right)=0,21 ; \mathrm{Ca}^{2+}\left(\mathrm{cmol}_{\mathrm{c}}\right.$ $\left.\mathrm{dm}^{-3}\right)=3,03 ; \mathrm{Mg}^{2+}\left(\mathrm{cmol}_{\mathrm{c}} \mathrm{dm}^{-3}\right)=1,45 ; \mathrm{Na}^{+}\left(\mathrm{cmol}_{\mathrm{c}}\right.$ $\left.\mathrm{dm}^{-3}\right)=2,56$; soma de bases $\left(\mathrm{cmol}_{\mathrm{c}} \mathrm{dm}^{-3}\right)=7,25$; capacidade de troca catiônica $\left(\mathrm{cmol}_{c} \mathrm{dm}^{-3}\right)=7,25$, 
(A)

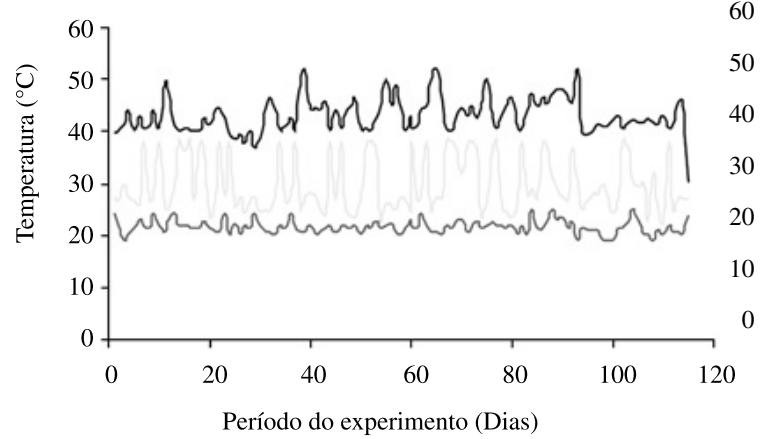

(B)
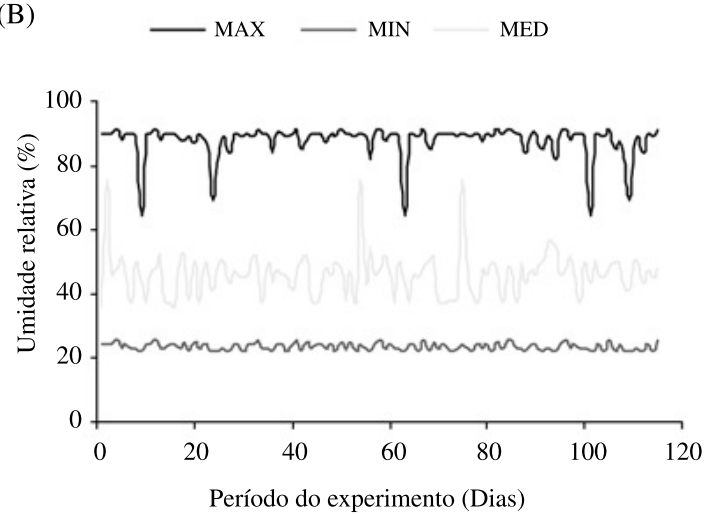

Figura 1. Valores de temperatura (A) e umidade relativa do ar (B) no interior do abrigo protegido no período de condução do experimento.

resultando no caráter eutrófico. Quanto aos atributos de salinidade, o material utilizado apresentou os seguintes teores: $\mathrm{pH}=8,38 ; \mathrm{Ca}^{2+}\left(\mathrm{mmol}_{\mathrm{c}} \mathrm{L}^{-1}\right)=$ 2,50; $\mathrm{Mg}^{2+}\left(\mathrm{mmol}_{\mathrm{c}} \mathrm{L}^{-1}\right)=3,87 ; \mathrm{Na}^{+}\left(\mathrm{mmol}_{\mathrm{c}} \mathrm{L}^{-1}\right)$ $=25,74 ; \mathrm{K}^{+}\left(\operatorname{mmol}_{\mathrm{c}} \mathrm{L}^{-1}\right)=0,35 ; \mathrm{Cl}^{-}\left(\operatorname{mmol}_{\mathrm{c}} \mathrm{L}^{-1}\right)=$ 18,$75 ; \mathrm{CO}_{3}^{2-}\left(\mathrm{mmol}_{\mathrm{c}} \mathrm{L}^{-1}\right)=0,00 ; \mathrm{HCO}_{3}^{-}\left(\mathrm{mmol}_{\mathrm{c}}\right.$ $\left.\mathrm{L}^{-1}\right)=5,50 ; \mathrm{SO}_{4}{ }^{2-}\left(\mathrm{mmol}_{\mathrm{c}} \mathrm{L}^{-1}\right)=0,00$; condutividade elétrica $\left(\mathrm{dS} \mathrm{m} \mathrm{m}^{-1}\right)=2,30$; relação de adsorção de sódio $\left(\mathrm{mmol} \mathrm{L}^{-1}\right)^{0,5}=14,42$ e percentagem de sódio trocável $(\%)=35,31$, conferindo o caráter sódico, segundo Richards (1954).

\section{Tratamentos e delineamento experimental}

Os tratamentos foram dispostos em blocos casualizados em parcelas subdivididas no tempo, sendo as parcelas compostas por cinco doses de biofertilizante bovino e nas sub parcelas as idades das plantas para avaliação. $\mathrm{O}$ biofertilizante foi aplicado ao solo na forma líquida aos níveis de 0 ; $25 ; 50 ; 75$ e $100 \%$ em volume correspondente à $10 \%$ ( $250 \mathrm{~mL}$ ) do volume do substrato diluído em água, exceto para o maior nível, e cinco idades de avaliação das plantas aos 45, 60, 75, 90, 105 dias após a semeadura - DAS, com quatro repetições, perfazendo um total de 100 unidades experimentais. Para taxa de crescimento absoluto e relativo, por serem variáveis dependentes de intervalo de tempo, a fonte de variação idades de avaliação foi desconsiderada, realizando um delineamento experimental apenas em blocos casualizados em quadruplicata, o mesmo sendo adotado para emergência de plântulas.

\section{Condução do experimento}

Cada unidade experimental foi constituída por um vaso plástico preto de forma cônica com diâmetro superior e inferior de 18,5 e 10,5 cm, respectivamente, e altura de $17,5 \mathrm{~cm}$ com capacidade para três litros contendo $2,5 \mathrm{~kg}$ de solo seco ao ar e passado em peneira de $6 \mathrm{~mm}$ com $2 \mathrm{~cm}$ de brita e 2 $\mathrm{cm}$ de areia, na base do vaso, mangueira e recipiente coletor de $2 \mathrm{~L}$ para avaliação da condutividade elétrica do lixiviado.

O biofertilizante bovino puro foi produzido sob fermentação anaeróbica, adicionando-se partes iguais de água e esterco fresco de bovino, permanecendo em recipiente hermeticamente fechado durante 30 dias (SANTOS, 1992; CAMPOS et al., 2008). A liberação do gás metano foi feita conectando-se uma das extremidades de uma mangueira na parte superior do biodigestor mantendo-se a outra imersa em um recipiente com água. Após as diluições referentes a cada tratamento procedeu-se as análises das misturas, disposta na Tabela 1.

A primeira aplicação do biofertilizante ocorreu 30 dias antes da semeadura, seguida de uma lavagem, fornecendo um volume de água não salina equivalente a duas vezes a porosidade total do solo $(1,31 \mathrm{~L})$. A segunda aplicação foi realizada 48 horas antes da semeadura e, em seguida, procedendo-se mais uma lavagem.

As sementes de maracujazeiro-amarelo (Passiflora edulis Sims Deg.), obtidas em plantio comercial no município de Remígio - PB, foram coletadas de frutos sadios, via seleção massal e postas para secar a sombra, e, posteriormente, eliminaram-se as defeituosas. Para assegurar mudas 
Tabela 1. Composição química da água e das misturas do biofertilizante bovino e águas utilizadas no experimento.

\begin{tabular}{lcrrrr}
\hline \multirow{2}{*}{ Atributos } & \multicolumn{5}{c}{ Biofertilizante $(\%)$} \\
\cline { 2 - 6 } & $0^{*}$ & 25 & 50 & 75 & 100 \\
\hline $\mathrm{pH}$ & 6,11 & 6,31 & 6,43 & 6,55 & 6,78 \\
$\mathrm{Ca}^{2+}\left(\mathrm{mmol}_{\mathrm{c}} \mathrm{L}^{-1}\right)$ & 1,25 & 3,91 & 6,21 & 9,27 & 10,53 \\
$\mathrm{Mg}^{2+}\left(\mathrm{mmol}_{\mathrm{c}} \mathrm{L}^{-1}\right)$ & 0,58 & 4,96 & 9,37 & 13,93 & 17,42 \\
$\mathrm{Na}^{+}\left(\mathrm{mmol}_{\mathrm{c}} \mathrm{L}^{-1}\right)$ & 0,92 & 2,33 & 4,01 & 4,68 & 6,24 \\
$\mathrm{~K}^{+}\left(\mathrm{mmol}_{\mathrm{c}} \mathrm{L}^{-1}\right)$ & 0,16 & 5,92 & 10,21 & 17,66 & 23,39 \\
$\mathrm{CO}_{3}^{2-}\left(\mathrm{mmol}_{\mathrm{c}} \mathrm{L}^{-1}\right)$ & 0,00 & 0,00 & 0,00 & 0,00 & 0,00 \\
$\mathrm{HCO}_{3}^{-}\left(\mathrm{mmol}_{\mathrm{c}} \mathrm{L}^{-1}\right)$ & 0,52 & 2,61 & 4,39 & 6,92 & 8,43 \\
$\mathrm{Cl}^{-}\left(\mathrm{mmol}_{\mathrm{c}} \mathrm{L}^{-1}\right)$ & 2,13 & 12,31 & 21,64 & 34,41 & 41,50 \\
$\mathrm{SO}_{4}^{2-}\left(\mathrm{mmol}_{\mathrm{c}} \mathrm{L}^{-1}\right)$ & 0,27 & 2,12 & 3,34 & 5,29 & 7,32 \\
$\mathrm{CE}_{\left(\mathrm{dS} \mathrm{m} \mathrm{m}^{-1}\right)}$ & 0,29 & 1,72 & 2,95 & 4,61 & 5,78 \\
$\mathrm{RAS}^{2}\left(\mathrm{mmol} \mathrm{L}^{-1}\right)^{0,5}$ & 0,96 & 1,11 & 1,43 & 1,38 & 1,67 \\
$\mathrm{Classificação*}^{* *}$ & $\mathrm{C}_{1} \mathrm{~S}_{1}$ & $\mathrm{C}_{3} \mathrm{~S}_{1}$ & $\mathrm{C}_{3} \mathrm{~S}_{1}$ & $\mathrm{C}_{4} \mathrm{~S}_{1}$ & $\mathrm{C}_{4} \mathrm{~S}_{1}$ \\
\hline
\end{tabular}

CE = Condutividade elétrica; RAS = Relação de adsorção de sódio; *= Água de irrigação; **=Classificação segundo Richards (1954).

vigorosas, testou-se a viabilidade das sementes $(92 \%)$, assegurando assim um material de boa qualidade. Foram semeadas seis sementes por unidade experimental, numa profundidade de $2 \mathrm{~cm}$ com solo previamente umedecido. A semeadura foi realizada no dia 12 de setembro de 2008. Após o período de estabilização da emergência das plântulas, aos 28 dias, realizou-se o desbaste, mantendo a planta mais vigorosa por unidade experimental.

A partir da semeadura até o final do experimento as irrigações foram realizadas mediante processo de pesagem, de modo a fornecer o volume evaporado no intervalo de 24 horas, elevando a umidade do solo à capacidade de campo.

\section{Variáveis observadas e análises estatísticas}

O percentual de plântulas emergidas foi determinado pela relação entre o número de plântulas emergidas e número de sementes postas para germinar por tratamento, multiplicando-se pela viabilidade das sementes (92\%).

Foram calculados, segundo Benincasa (2003): alocação de biomassa nos diferentes órgãos (raiz, caule e folhas); Taxa de crescimento absoluto (TCA) e taxa de crescimento relativo (TCR), sendo as duas últimas no intervalo de 45-60, 60-75, 75-90 e 90-105 dias após a semeadura, utilizando as seguintes expressões:

Alocação de biomassa órgão $=($ MSórgão / MStotal) x 100

Taxa de crescimento absoluto $=(\mathrm{MSf}-\mathrm{MSi}) / \Delta \mathrm{t}$

Razão de área foliar $=$ AFf $/$ MStotal
Taxa de assimilação líquida $=[(\ln \mathrm{AFf}-\ln$ $\mathrm{AFi}) / \mathrm{AFf}-\mathrm{AFi})] \times[(\mathrm{MSf}-\mathrm{MSi}) / \Delta \mathrm{t}]$

Onde: MSórgão = fitomassa seca nos diferentes órgãos; MStotal = fitomassa seca total; MSf é fitomassa seca total final; MFórgão = fitomassa fresca nos diferentes órgãos; AFi é área foliar inicial; AFf é área foliar final; ln é o logaritmo neperiano e t é a duração em dias.

Os resultados foram submetidos à análise de variância, sendo o nível de significância determinado pelo teste "F" e as médias comparadas pelo teste de Tukey a 5\% de probabilidade e ainda submetidos à análise de regressão polinomial (Ferreira, 2000), utilizando o software SAEG 8.0.

\section{RESULTADOS E DISCUSSÃO}

O potencial germinativo do maracujazeiro amarelo foi influenciado estatisticamente pelas doses do biofertilizante bovino líquido (Figura 2). A percentagem de emergência foi mais expressiva nos tratamentos contendo maior proporção de biofertilizante, com uma superioridade de 56,48\% em relação aos tratamentos sem o insumo.

Esses resultados diferem da literatura em geral, uma vez que os solos afetados por sais comprometem a emergência e o crescimento inicial da grande maioria das culturas (Carneiro et al., 2002 e Costa et al., 2005). Entretanto, alguns estudos comprovam melhora da percentagem de emergência em substratos contendo biofertilizante bovino fermentado em mamoneira (Campos et al., 2009) e maracujazeiro amarelo (Sousa, 2006). Segundo os autores, o insumo 


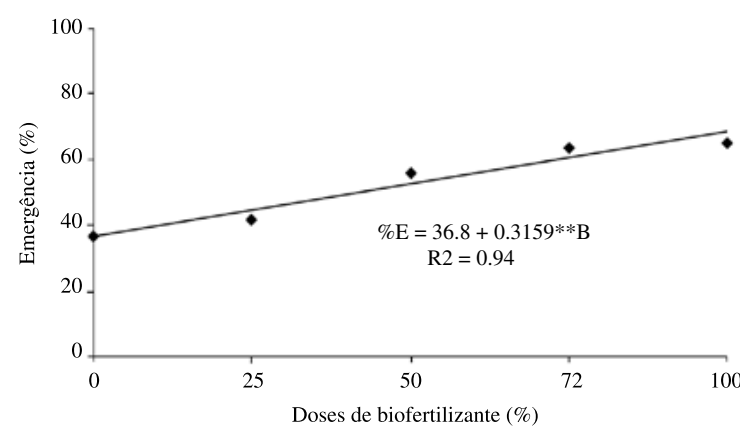

Figura 2. Percentagem de emergência de plântulas de maracujazeiro amarelo em função do biofertilizante bovino aplicado em solo sódico.

provavelmente exerça ação mitigadora dos sais estimulando o ajustamento osmótico das sementes. Outra possibilidade é favorecer o deslocamento de reservas dos cotilédones para os demais órgãos, reduzindo os efeitos adversos da salinidade.

Observa-se efeito significativo ( $\mathrm{p} \leq 0,01)$ as doses de biofertilizante bovino exerceram efeitos significativos sobre a taxa de crescimento absoluto nos intervalos de 45-60 e 75-90 e 60-75 e 90-105 dias apenas ao nível de 5\% de probabilidade, mas influenciaram estatisticamente a taxa de assimilação líquida (Tabela 2). A análise de crescimento é considerada internacionalmente como o método padrão para a estimativa da produtividade biológica, ou produtividade primária das comunidades vegetais (Benincasa, 2003). Segundo a autora, somente dois tipos de medidas são necessárias para se fazer a análise de crescimento: a) a massa da planta (geralmente dado em massa seca) e b) o tamanho do sistema assimilatório (dado em área foliar ou conteúdo de clorofila).

A taxa de crescimento absoluto pode ser usada para estimar a velocidade média de crescimento ao longo do período (Benincasa, 2003), a qual foi determinada em função das cinco idades de avaliação (Figura 3). No período de 45 e 60 dias, as plantas tratadas com $100 \%$ do biofertilizante bovino tiveram o crescimento cerca de $52 \%$ superior comparativamente à testemunha (Figura 3A), observando a mesma tendência para as demais épocas de avaliação (Figuras 3B, 3C e 3D), notando-se que, com a elevação da concentração do insumo, houve acréscimo na taxa de crescimento absoluto do maracujazeiro amarelo no solo comprometido por sódio trocável. Numa avaliação geral, constata-se que o maracujazeiro amarelo cresceu mais rapidamente no último período de avaliação com incremento unitário de $0,0007 \mathrm{~g}$ $\mathrm{dia}^{-1}$ por incremento percentual de biofertilizante bovino. Além do possível efeito benéfico do biofertilizante bovino, ao final do experimento, uma relativa redução da temperatura média da casa de vegetação foi observada (Figura 1), podendo ter contribuído para maior absorção de nutrientes e, em consequência, uso eficiente de água.

Conforme os resumos das análises de variância apresentados na Tabela 3, observa-se que, exceto sobre a razão de área foliar, a interação biofertilizante $\mathrm{x}$ idade das plantas não exerceu efeito sobre as demais variáveis analisadas, entretanto o biofertilizante interferiu isoladamente sobre a alocação de biomassa do maracujazeiro amarelo para as raízes e folhas, respectivamente.

Quanto aos dados da alocação de biomassa, que expressa a translocação de compostos orgânicos para diferentes órgãos das plantas (Benincasa, 2003), mesmo havendo registro de efeitos significativos do biofertilizante bovino, a alocação de biomassa para as raízes (Figura 4A) e para as folhas (Figura 4B), os dados não se ajustaram a nenhum modelo de regressão, com valores médios de 32,05 e 38,81\%, respectivamente).

Tabela 2. Resumo das análises de variância referentes à taxa de crescimento absoluto entre 45-60 dias (TCA1), 60-75 dias (TCA2), 75-90 dias (TCA3), 90-105 dias (TCA4) e taxa de assimilação líquida entre 45-105 (TAL) do maracujá amarelo submetido à biofertilizante bovino em solo sódico.

\begin{tabular}{lcccccc}
\hline \multirow{2}{*}{ Fonte de Variação } & GL & \multicolumn{5}{c}{ Quadrado médio } \\
\cline { 3 - 7 } & & TCA1 & TCA2 & TCA3 & TCA4 & TAL \\
\hline Blocos & 3 & $0,00002^{\text {ns }}$ & $0,00006^{\text {ns }}$ & $0,0004^{\text {ns }}$ & $0,0009^{\text {ns }}$ & $3,3 \times 10^{-6} \mathrm{~ns}$ \\
Biofertilizante (B) & 4 & $0,00045^{* *}$ & $0,00041^{*}$ & $0,0083^{* *}$ & $0,0055^{*}$ & $1 \times 10^{-5} \mathrm{~ns}$ \\
Resíduo & 12 & 0,00007 & 0,00011 & 0,0009 & 0,00084 & $4,1 \times 10^{-6} \mathrm{~ns}$ \\
Total & 19 & - & - & - & - & - \\
CV $(\%)$ & - & 16,47 & 23,26 & 19,02 & 25,01 & 40,18 \\
\hline
\end{tabular}

${ }^{\mathrm{ns}}=$ não significativo $; \mathrm{e}^{* *}$ significativos para $\mathrm{p}<0,05 \mathrm{e} \mathrm{p}<0,01$, respectivamente; $\mathrm{CV}=$ Coeficiente de variação. 
Tabela 3. Resumo das análises de variância referentes à razão de área foliar (RAF), área foliar específica (SF), alocação de biomassa para raiz $(\mathrm{ABR})$, caule $(\mathrm{ABC})$ e folhas $(\mathrm{ABF})$ do maracujazeiro-amarelo submetido à biofertilizante bovino em solo sódico.

\begin{tabular}{lccccc}
\hline \multirow{2}{*}{ Fonte de Variação } & GL & \multicolumn{4}{c}{ Quadrado médio } \\
\cline { 3 - 6 } & & RAF & ABR & ABC & ABF \\
\hline Blocos & 3 & $517,11^{\text {ns }}$ & $4,019^{\text {ns }}$ & $12,390^{\text {ns }}$ & $92,15^{\text {ns }}$ \\
Biofertilizante (B) & 4 & $5815,36^{\text {ns }}$ & $146,93^{* *}$ & $23,456^{\text {ns }}$ & $123,41^{*}$ \\
Resíduo-a & 12 & 1148,35 & 25,625 & 37,237 & 34,057 \\
CV-a (\%) & - & 45,35 & 15,79 & 20,40 & 14,94 \\
Idade de avaliação (I) & 4 & $7947,07^{* *}$ & $53,312^{\text {ns }}$ & $40,15^{\text {ns }}$ & $70,235^{\text {ns }}$ \\
Interação B x I & 16 & $1591,82^{\text {ns }}$ & $64,008^{\text {ns }}$ & $68,88^{\text {ns }}$ & $121,79^{\text {ns }}$ \\
Resíduo-b & 60 & 1527,71 & 81,559 & 32,204 & 68,979 \\
CV-b (\%) & - & 35,98 & 28,17 & 18,96 & 21,26 \\
Total & 99 & - & - & - & - \\
\hline
\end{tabular}

${ }^{\mathrm{ns}}=$ não significativo; $*$ e ** significativos para $\mathrm{p}<0,05 \mathrm{e} \mathrm{p}<0,01$, respectivamente pelo teste $\mathrm{F} ; \mathrm{CV}=\mathrm{Coeficiente}$ de variação.
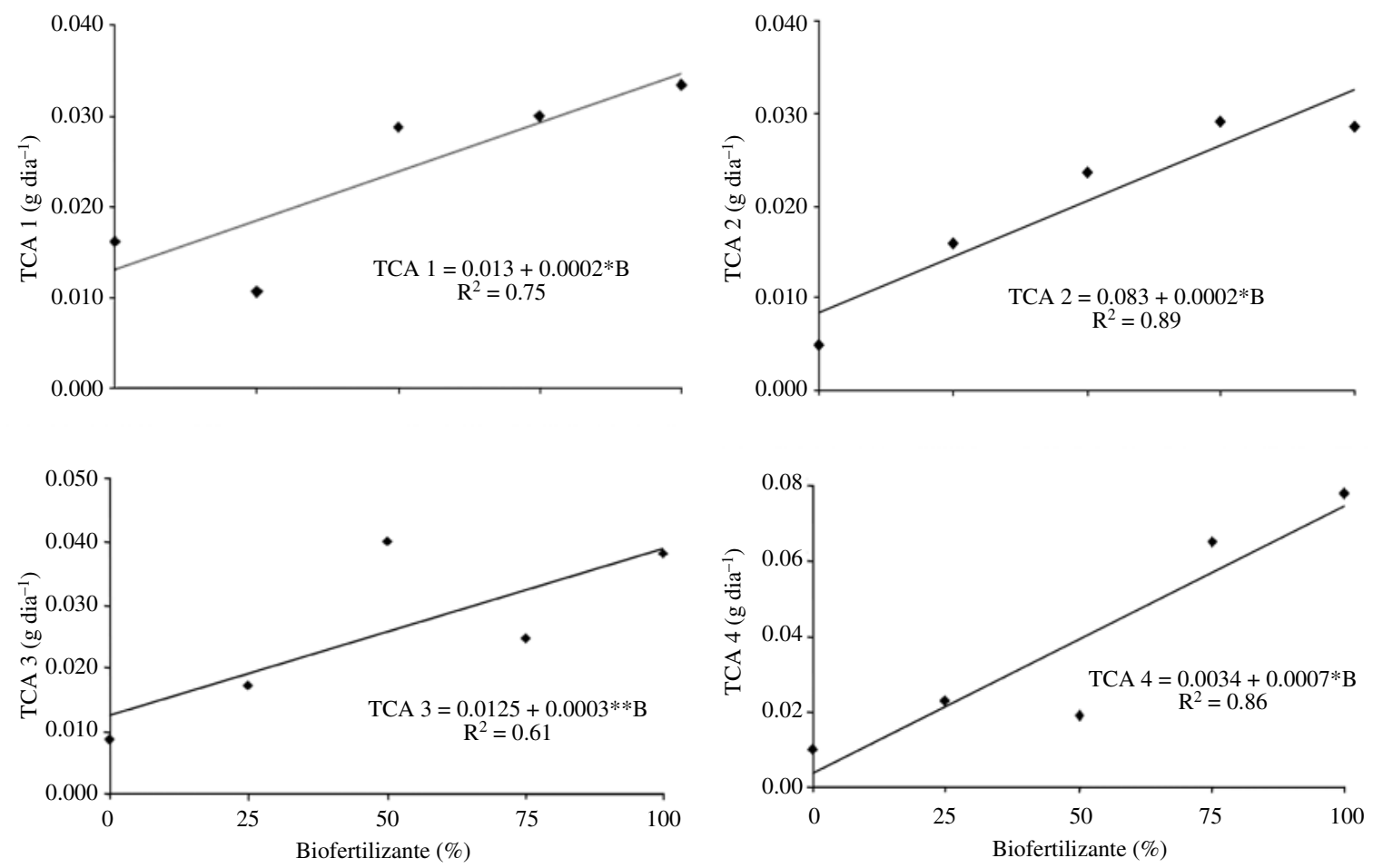

Figura 3. Taxa de crescimento absoluto entre 45-60 dias (TCA 1), 60-75 dias (TCA2), 75-90 dias (TCA3) e 90-105 dias (TCA 4) em função do biofertilizante bovino aplicado ao solo sódico.

Esses resultados divergem dos apresentados por Cavalcante et al. (2008) após avaliarem a alocação de biomassa em solo não salino irrigado com águas de $0,5,1,5$ e 2,5 $\mathrm{dS} \mathrm{m}^{-1}$ e constataram que o aumento da salinidade da água comprometeu a produção de biomassa e a alocação para os órgãos do maracujazeiro amarelo.
Quanto aos dados da alocação de biomassa, que expressa a translocação de compostos orgânicos para diferentes órgãos das plantas (BENINCASA, 2003), mesmo havendo registro de efeitos significativos do biofertilizante bovino, a alocação de biomassa para as raízes (Figura 4A) e para as folhas (Figura 4B), os dados não se ajustaram a nenhum modelo de 
regressão, com valores médios de 32,05 e 38,81\%, respectivamente). Esses resultados divergem dos apresentados por Cavalcante et al. (2008) após avaliarem a alocação de biomassa em solo não salino irrigado com águas de $0,5,1,5$ e 2,5 $\mathrm{dS} \mathrm{m}^{-1}$ e constataram que o aumento da salinidade da água comprometeu a produção de biomassa e a alocação para os órgãos do maracujazeiro amarelo.
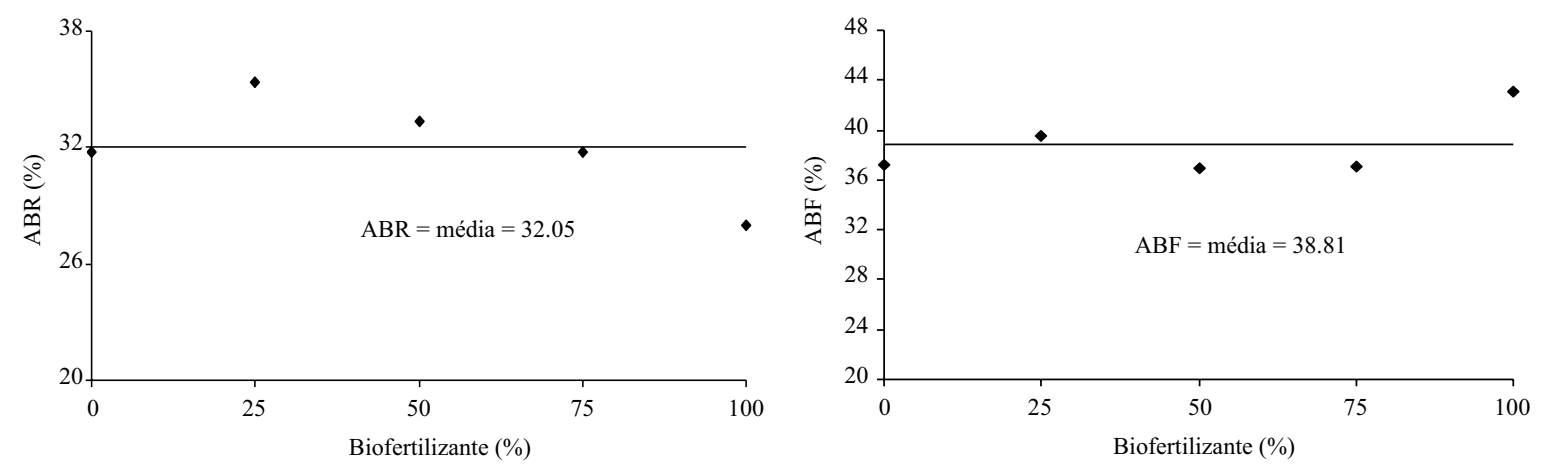

Figura 4. Alocação de biomassa para as raízes (A) e folhas (B) do maracujazeiro amarelo submetido à aplicação de biofertilizante bovino em solo sódico.

\section{Conclusão}

O biofertilizante bovino líquido promoveu maior emergência de plântulas e o crescimento do maracujazeiro amarelo.

\section{Agradecimentos}

Ao Conselho Nacional de Desenvolvimento Científico e Tecnológico (CNPq) pelo financiamento da pesquisa e a Coordenação de Aperfeiçoamento de Pessoal de Nível Superior (CAPES) pela concessão de bolsa de pós-graduação ao primeiro autor.

\section{Referências Citadas}

Benincasa, M.M.P.

2003 Análise de crescimento de plantas. $2^{\mathrm{a}}$ ed. Jaboticabal: FUNEP, $41 \mathrm{p}$.

Bissani, C.A.; Meurer, E.J.; Bohnen, H.

2006 Solos ácidos e solos afetados por sais. In: MEURER, E.J. (Ed). Fundamentos da química do solo. $3^{\mathrm{a}}$ ed. Porto Alegre: Genesis, 2006. Cap. 6, p.198-202.

Campos, V. B.; Cavalcante, L.F.; Rodolfo Júnior, F.; Sousa, G.G.; Mota, J.K.M.

2009 Crescimento inicial da mamoneira submetido à irrigação com água salina e biofertilizante bovino. Magistra, Cruz das Almas, v. 21, p. 40-47.

Campos, V.B.; Cavalcante, L.F.; Morais, T.A.; Menezes Junior, J.C.; Prazeres, S.S.

2008 Potássio, biofertilizante e cobertura morta: Efeito sobre o crescimento do maracujazeiro amarelo. Revista Verde, v.3, n.1, p.78-86.

Carneiro, P.T.; Fernandes, P.D.; Gheyi, H.R.; Soares, F.A.L.

2002 Germinação e crescimento inicial de genótipos de cajueiro anão-precoce em condições de salinidade. Revista Brasileira de Engenharia Agrícola e Ambiental, v.6, n.2, p. 199-206.
Cavalcante, L. F.; Cavalcante, I. H. L.; Hu, Y.; BeckmannCavalcante, M. Z.

2007 Water salinity and initial development of four guava (Psidium guajava L.) cultivar in north-eastern Brazil. Journal of Fruit and Ornamental Plant Research, Skierniewice, v. 15, p. 71-80.

Cavalcante, L.F.; Silva, M.N.B.; Diniz, A.A.; Cavalcante, I.H.L.; Campos, V.B.

2008 Biomassa do maracujazeiro amarelo em solo irrigado com água salina protegido contra perdas hídricas. Revista Verde, v.3, n.3, p. 26-34.

Cavalcante, L.F.; Vieira, M.S.; Santos, A.F.; Oliveira, W.M.; Nascimento, J.A.M.

2010 Água salina e esterco bovino líquido na formação de mudas de goiabeira cultivar Paluma. Revista Brasileira de Fruticultura, Jaboticabal, v.32, n.1, p. 251-261.

Costa, E. G.; Carneiro, P. T.; Soares, F. A. L.; Dantas, P. F.; Gheyi, H. R.

2005 Crescimento inicial do maracujazeiro-amarelo sob diferentes tipos e níveis de salinidade da água de irrigação. Revista Brasileira de Engenharia Agrícola e Ambiental, Campina Grande, v.9, n.4, p.242-247. 
Empresa Brasileira De Pesquisa Agropecuária-Embrapa. 1997 Centro Nacional de Pesquisa de Solos. Manual de métodos de analise de solo. 2.ed. Rio de Janeiro: EMBRAPA. (Documentos, 1).

Ferreira, P. V.

2000 Estatística experimental aplicada à agronomia. 3.ed. Maceió: EDUFAL.

Garcia, G.O.; Ferreira, P.A.; Miranda, G.V.; Neves, J.C.; Moraes, W.B.; Santos, D.B.

2007 Teores foliares dos macronutrientes catiônicos e suas relações com o sódio em plantas de milho sob estresse salino. Revista Idesia, Arica, v.25, n.3, p.93-106.

Marschner, $\mathrm{H}$.

1995 Mineral nutrition of higher plant. 2. ed. Academy, New York, $889 \mathrm{p}$.

Meza, N.; Arizaleta, M.; Bautista, D.

2007 Efecto de la salinidad en la germinación y emergencia de semillas de particha (Passiflora edulis $f$. flavicarpa). Revista de la Faculdad de Agronomía Luz, Maracaibo, v.24, n.4, p. 46-53.

Munns, R.; James, R.A.; Läuchli, A.

2006 Approaches to increasing the salt tolerance of wheat and other cereals. Journal of Experimental Botany, Oxford v. 57 , p. $1025-1043$.
Richards, L.A.

1954 Diagnostico y rehabilitacion de suelos salinos y sodicos. Departamento de Agricultura de los Estados Unidos de la America, 172p. (Manual de Agricultura, 60).

Santos, A.C.V.

1992 Biofertilizante líquido: o defensivo agrícola da natureza. 2.ed. Niterói: EMATER-RJ. (Agropecuária Fluminense, 8).

Silva, E. C.; Nogueira, R. J. M. C.; Araújo, F. P.; Melo N. F.; Azevedo Neto.

2008 Phisiological responses to salt stress in Young umbu plants. Enviromental and Experimental Botany, Oxford, v. 63 , p. $147-157$.

Sousa, G.B.

2006 Interação biofertilizante $x$ salinidade $x$ volume de substrato na emergência e crescimento inicial do maracujazeiro amarelo. Dissertação (Mestrado em Manejo de Solo e Água)-Centro de Ciências Agrárias. Universidade Federal da Paraíba, Areia. 72f.

Zhu, J.K.

2001 Plant salt torelance-Review. Trends in Plant Science, v.6, n.2, p.1-5. 